\title{
Alpha-decay damage and recrystallization in zircon: evidence for an intermediate state from infrared spectroscopy
}

\author{
M Zhang $\dagger$, E K H Salje†, R C Ewing †, I Farnan $\dagger$, S Ríos $\dagger$, J Schlüter§ and \\ P Leggo $\dagger$ \\ $\dagger$ Department of Earth Sciences, University of Cambridge, Downing Street, \\ Cambridge CB2 3EQ, UK \\ \$Department of Nuclear Engineering and Radiological Sciences, \\ Department of Geological Sciences, University of Michigan, Ann Arbor, MI 48109-22104, USA \\ $\S$ Mineralogisches Museum, Mineralogisch-Petrographisches Institut, Universität Hamburg, \\ Grindelallee 48, D-20146 Hamburg, Germany \\ E-mail: mz10001@esc.cam.ac.uk
}

Received 22 March 2000

\begin{abstract}
. $\alpha$-decay damage and recrystallization in natural zircon (with dose ranging from 0.06 to $23.3 \times 10^{18} \alpha$-events $\mathrm{g}^{-1}$ ) were studied using polarized reflection infrared spectroscopy. The experimental results show that $\alpha$-decay damage leads to a gradual decrease in reflectivity and a loss of anisotropy of IR spectra. Recrystallization of damaged zircon is found as a multi-stage process with a strong dependence on the initial degree of damage. In weakly and moderately damaged samples the major recrystallization takes place near $1000 \mathrm{~K}$. Annealed samples recrystallize epitaxially along their original crystallographic orientations. A highly damaged zircon with radiation dose of $15.9 \times 10^{18} \alpha$-events $\mathrm{g}^{-1}$ decomposes into $\mathrm{SiO}_{2}$ and $\mathrm{ZrO}_{2}$ near $1100 \mathrm{~K}$. In this sample the growth of $\mathrm{ZrSiO}_{4}$ from the binary oxides occurs between 1400 and $1500 \mathrm{~K}$. An additional IR signal peaked near $790 \mathrm{~cm}^{-1}$ is detected in moderately damaged samples annealed at temperatures higher than $800 \mathrm{~K}$. This peak is sharp and isotropic. The peak tends to disappear at temperatures above $1400 \mathrm{~K}$. This signal may be related to an unknown intermediate phase caused by heating of radiation-damaged zircon. Alternatively, the signal may be due to the structural distortions near the boundaries between the amorphized and crystalline regions.
\end{abstract}

\section{Introduction}

Natural zircon $\left(\mathrm{ZrSiO}_{4}\right)$ commonly contains $\mathrm{U}$, Th and other rare earth elements. Due to radioactive decay of naturally occurring radionuclides and their daughter products in the ${ }^{238} \mathrm{U}$, ${ }^{235} \mathrm{U}$ and ${ }^{232} \mathrm{Th}$ decay series the structure of zircon can be heavily damaged over geological times, resulting in a partially aperiodic state, the so-called metamict state [1].

It is unclear whether metamictization in zircon involves the formation of intermediate phases. In an X-ray and optical investigation [2], a systematic development and disappearance of an extra peak near $2 \theta$ of $35-36.5^{\circ}$ was observed with increasing degree of $\alpha$-decay radiation damage. The authors found no appreciable variability that could be related to inhomogeneity, and proposed the formation of an intermediate polycrystalline phase with intermediate dose. On the other hand, this peak splitting was explained to be due to the coexistence of two phases with different degrees of damage [3], implying a heterogeneous degree of radiation damage. Heterogeneity cannot, however, explain the observation of an IR peak near $800 \mathrm{~cm}^{-1}$ in moderately damaged samples that were annealed at high temperatures $[4,5]$. 
Table 1. Zircon sample descriptions. Density is in units of $\mathrm{g} \mathrm{cm}^{-3}$ and dosage in units of $10^{18}$ $\alpha$-events $\mathrm{g}^{-1}$.

\begin{tabular}{llllllll}
\hline Zircon & Locality & Density & Dosage & $a(\AA)$ & $c(\AA)$ & $V\left(\AA^{3}\right)$ & Reference/source \\
\hline $4403^{\text {a }}$ & Sri Lanka & 4.72 & 0.06 & 6.6085 & 5.9845 & 261.36 & {$[3]$} \\
$3104^{\text {b }}$ & Sri Lanka & 4.68 & 1.0 & & ND & & {$[8]$} \\
Moroto & Uganda & ND & ND & 6.6056 & 5.9834 & 261.08 & {$[6]$} \\
269 & Sri Lanka & ND & 1.8 & 6.6301 & 6.0266 & 264.91 & {$[11]$} \\
$4605^{\text {a }}$ & Sri Lanka & 4.58 & 2.0 & 6.645 & 6.047 & 267.01 & {$[3]$} \\
$6404^{\text {b }}$ & Sri Lanka & 4.54 & 3.5 & 6.68 & 6.07 & 271 & {$[3]$} \\
Z1 & Norway & ND & ND & 6.64 & 6.12 & 270 & HAM \\
$4105^{\text {a }}$ & Sri Lanka & 4.25 & 6.3 & 6.70 & 6.13 & 275 & {$[3]$} \\
Ni12 & Sri Lanka & ND & 7.1 & \multicolumn{5}{c}{ ND } & \\
Z2 & Sri Lanka & 4.03 & 8.6 & ND & {$[11]$} \\
Ti8 & Sri Lanka & 4.04 & 9.6 & unable to determine $a$ and $c$ & {$[11]$} \\
$6500^{c}$ & Sri Lanka & ND & 11.7 & unable to determine $a$ and $c$ & {$[7]$} \\
157 & Sri Lanka & 3.96 & 13.1 & \multicolumn{5}{c}{ ND } & \\
Sd4 & Sri Lanka & ND & 15.9 & \multicolumn{5}{c}{ ND } & \\
82988 & Sri Lanka & ND & 23.5 & \multicolumn{5}{c}{ ND } & {$[11]$} \\
\hline
\end{tabular}

$\mathrm{ND}=$ not determined

${ }^{\text {a }}$ Measured by Murakami et al [3].

${ }^{\mathrm{b}}$ Measured by Ellsworth et al [8].

${ }^{\mathrm{c}}$ Measured by Woodhead et al [7].

HAM = Mineralogisches Museum, Mineralogisch-Petrographisches, Universität Hamburg, Germany.

Furthermore, in a recent Raman study of recrystallization of metamict zircon [6], it was found that annealing damaged zircon samples between 800 and $900 \mathrm{~K}$ resulted in additional Raman bands at 670,798 and $1175 \mathrm{~cm}^{-1}$ and with further heating to above $1400 \mathrm{~K}$ these signals became too weak to be detected. Prolonged annealing at $1050 \mathrm{~K}$ led to the disappearance of these signals [6]. This observation suggested the possible existence of an intermediate phase. We undertook this IR study to further investigate the recrystallization process and the possible appearance of an intermediate structural state. We argue that the recrystallization in damaged zircon is a multi-stage process (as observed in a previous Raman investigation [6]) with extra IR band(s) appearing near $800 \mathrm{~K}$.

\section{Experiment}

Natural zircon gemstones with a range of degrees of radiation damage $\left(0.06-23.5 \times 10^{18}\right.$ $\alpha$-events $\mathrm{g}^{-1}$ ) were used in this study. Fourteen of the 15 samples have been previously studied [3, 6-12]. The radiation dose was determined for samples from Sri Lanka because of their well defined geological age (570 \pm 20 million years) [3]. The samples have been characterized using different analytic methods: infrared and Raman spectroscopy, TEM, x-ray diffraction and electron microprobe. The sample descriptions are given in table 1 . The chemical compositions of all the samples except $\mathrm{Z} 1$ can be found in previous publications as listed in table 1. Electron microprobe analyses of sample $\mathrm{Z} 1$ show the following wt\% oxides: $\mathrm{SiO}_{2}$ 32.52, $\mathrm{ZrO}_{2}$ 64.98, $\mathrm{HfO}_{2}$ 2.44, $\mathrm{CaO}$ 0.01, $\mathrm{Y}_{2} \mathrm{O}_{3}$ 0.65, $\mathrm{ThO}_{2}$ 0.07, $\mathrm{UO}_{2}$ 0.37. FeO and $\mathrm{Al}_{2} \mathrm{O}_{3}$ were not detected. Due to the lack of the information on its geological age, the radiation dose of $\mathrm{Z} 1$ is estimated to be $3.8 \times 10^{18} \alpha$-events $\mathrm{g}^{-1}$ using the dose-linewidth and dose-frequency dependences reported by Zhang et al [11]. The uncertainty due to the estimation is less than $1 \times 10^{18} \alpha$-events $\mathrm{g}^{-1}$. 
The crystallographic orientation of each crystal was determined morphologically or using $\mathrm{x}$-ray precession techniques and optical polarizing microscopy. Samples with doses higher than $10 \times 10^{18} \alpha$-events $\mathrm{g}^{-1}$ could not be oriented as no Bragg reflections were found and these high-dose samples all have irregular external shapes. In the case of crystalline zircon, plates were cut parallel to the $c$-axis and polished. All annealing experiments were carried out in $\mathrm{N}_{2}$ atmosphere in a vertical furnace. Two Pt-PtRh thermocouples were used in the furnace: one was coupled with an Eurotherm temperature controller. The second Pt-PtRh thermocouple was used to monitor the annealing temperature. The instability of the annealing temperature is less than $5 \mathrm{~K}$. The crystals were annealed at a designated temperature for one hour and subsequently quenched in air. Samples were measured at room temperature before being annealed again at a higher temperature.

An infrared microscope equipped with a mapping stage and attached to a Bruker IFS 66v FT-IR spectrometer was used to record reflection spectra between 650 and $5000 \mathrm{~cm}^{-1}$ at an almost normal incident condition. The beam size was $150 \mu \mathrm{m}$. A liquid-nitrogen-cooled MCT detector, coupled with a KBr beamsplitter and a Globar source were used. The spectra were averaged by 1000 (for heavily damaged samples) and 512 scans (for weakly damaged samples) with a spectral resolution of $4 \mathrm{~cm}^{-1}$. Gold mirrors and a KRS5 wire-grind polarizer were used.

\section{Results}

Seven infrared-active normal modes $\left(3 \mathrm{~A}_{2 u}+4 \mathrm{E}_{u}\right)$ are predicted by group theory in zircon at $\boldsymbol{k}=\mathbf{0}$ [13]. According to selection rules the resonances of $\mathrm{E}_{u}$ symmetry are observed when the electric vector of the incident infrared radiation is perpendicular to the $c$ axis while those of $\mathrm{A}_{2 u}$ symmetry are observed when the electric vector is parallel to $c$.

The reflection spectrum of zircon between 650 and $1400 \mathrm{~cm}^{-1}$ is characterized by $\mathrm{Si}-\mathrm{O}$ stretching $\nu_{3}$ vibrations $\left(\mathrm{E}_{u}\right.$ mode at $885 \mathrm{~cm}^{-1}$ and $\mathrm{A}_{2 u}$ mode at $989 \mathrm{~cm}^{-1}$ ) (figure 1). The effects of $\alpha$-decay radiation damage on the structure of zircon are seen as a systematic decrease in reflectivity and a gradual loss of anisotropy. Well crystallized samples 4403 and 3104 (with dose of 0.06 and $1.0 \times 10^{18} \alpha$-events $\mathrm{g}^{-1}$, respectively) (figures 1 and 2) show band shapes and reflectivity between 650 and $1400 \mathrm{~cm}^{-1}$ similar to those reported by Dawson et al [13], and the polarized spectra measured with $\boldsymbol{E}$ perpendicular and parallel to the $c$ axis show clearly the $\mathrm{E}_{u}$ mode at $885 \mathrm{~cm}^{-1}$ and $\mathrm{A}_{2 u}$ mode at $989 \mathrm{~cm}^{-1}$, respectively. Moderately damaged samples 4605, 4604 and 4105 (with dose of 2.0, 3.5 and $6.3 \times 10^{18} \alpha$-events $\mathrm{g}^{-1}$, respectively) exhibit a decrease in reflectivity and a loss of anisotropy (figures 1 and 2) with increasing dose. Weak orientation dependence is still seen in sample Ti8 $\left(9.6 \times 10^{18} \alpha\right.$-events $\left.\mathrm{g}^{-1}\right)$ (figure 1). It was not possible to orient samples 6500, 157, Sd4 and 82988 (with dose of 11.7, 13.1, 15.9 and $23.5 \times 10^{18} \alpha$-events $\mathrm{g}^{-1}$, respectively). A crystal of sample 82988 was cut into a cube (about $2 \mathrm{~mm}$ in size) and polarized reflection measurements were performed on its three perpendicular surfaces. The polarized spectra obtained from these different planes with different polarization conditions show essentially identical spectral features within the experimental resolution. Polarized spectra from one surface of the crystal are shown in figure 1 .

One of the most important spectra changes is the gradual development of IR signals between 1050 and $1150 \mathrm{~cm}^{-1}$ (as indicated by an arrow in figure 2) with increasing dose. Although the spectra in this range show broad features, the spectra are essentially identical when dose is higher than $10 \times 10^{18} \alpha$-decay $\mathrm{g}^{-1}$ and the spectra of heavily damaged samples are different from those of the $\mathrm{Si}-\mathrm{O}$ stretching vibrations from $\mathrm{SiO}_{2}$ glass (figure 2).

Annealing sample Moroto (well crystallized) for one hour between $700 \mathrm{~K}$ and $1700 \mathrm{~K}$ does not lead to significant changes of IR spectra (figure 3(a)). For sample 269 (weakly damaged, 

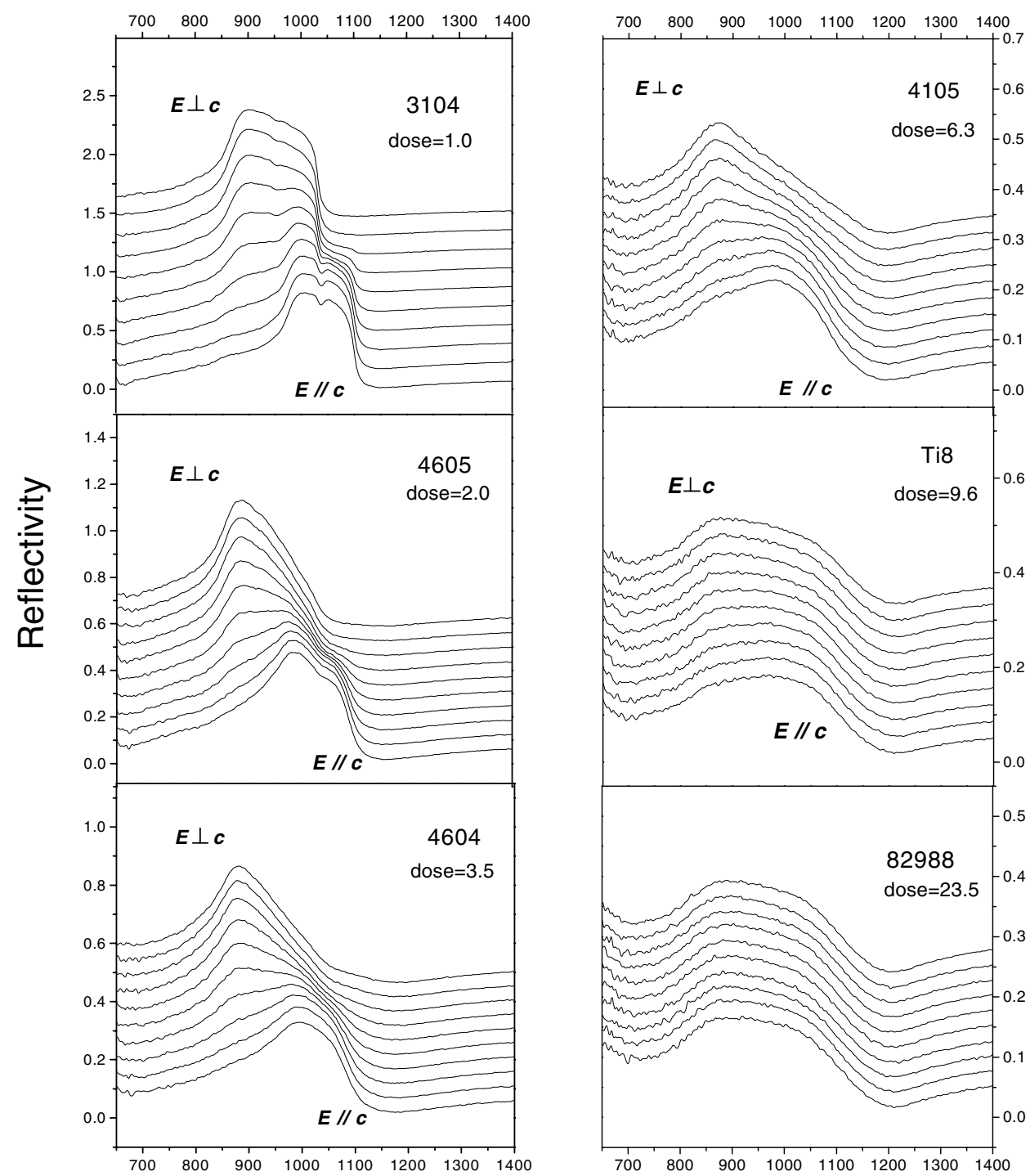

\section{Wavenumber $\left(\mathrm{cm}^{-1}\right)$}

Figure 1. Stacked plots of polarized infrared reflection spectra between 650 and $1400 \mathrm{~cm}^{-1}$ of zircon samples with different degrees of $\alpha$-decay radiation damage. Radiation dosage is in units of $10^{18} \alpha$-events $\mathrm{g}^{-1}$. Crystal zircon plates were cut parallel to the $c$ axis. The spectra are shifted to show details and the interval of the angle between the $\boldsymbol{c}$ axis and $\boldsymbol{E}$ (electric field) is $10^{\circ}$. Spectra of sample 82998 were from a crystal with unknown original crystallographic orientation because of its high dose (see more details in text).

dose $=1.8 \times 10^{18} \alpha$-events $\left.\mathrm{g}^{-1}\right)$, a slight increase in reflectivity from $\mathrm{ZrSiO}_{4}$ is already seen near $800 \mathrm{~K}$ (figure $3(\mathrm{~b})$ ). Annealed at high temperatures, the more damaged sample Z1 (estimated dose $=3.8 \times 10^{18} \alpha$-events $\mathrm{g}^{-1}$ ) shows a weak increase in reflectivity starting near $700 \mathrm{~K}$ (figure 4(a)). In order to obtain quantitative analysis, reflectivity at $990 \mathrm{~cm}^{-1}$ for $\boldsymbol{E} \| \boldsymbol{c}$ and $890 \mathrm{~cm}^{-1}$ for $\boldsymbol{E} \perp \boldsymbol{c}$, respectively, is plotted as a function of temperature (figure 4(b)). 


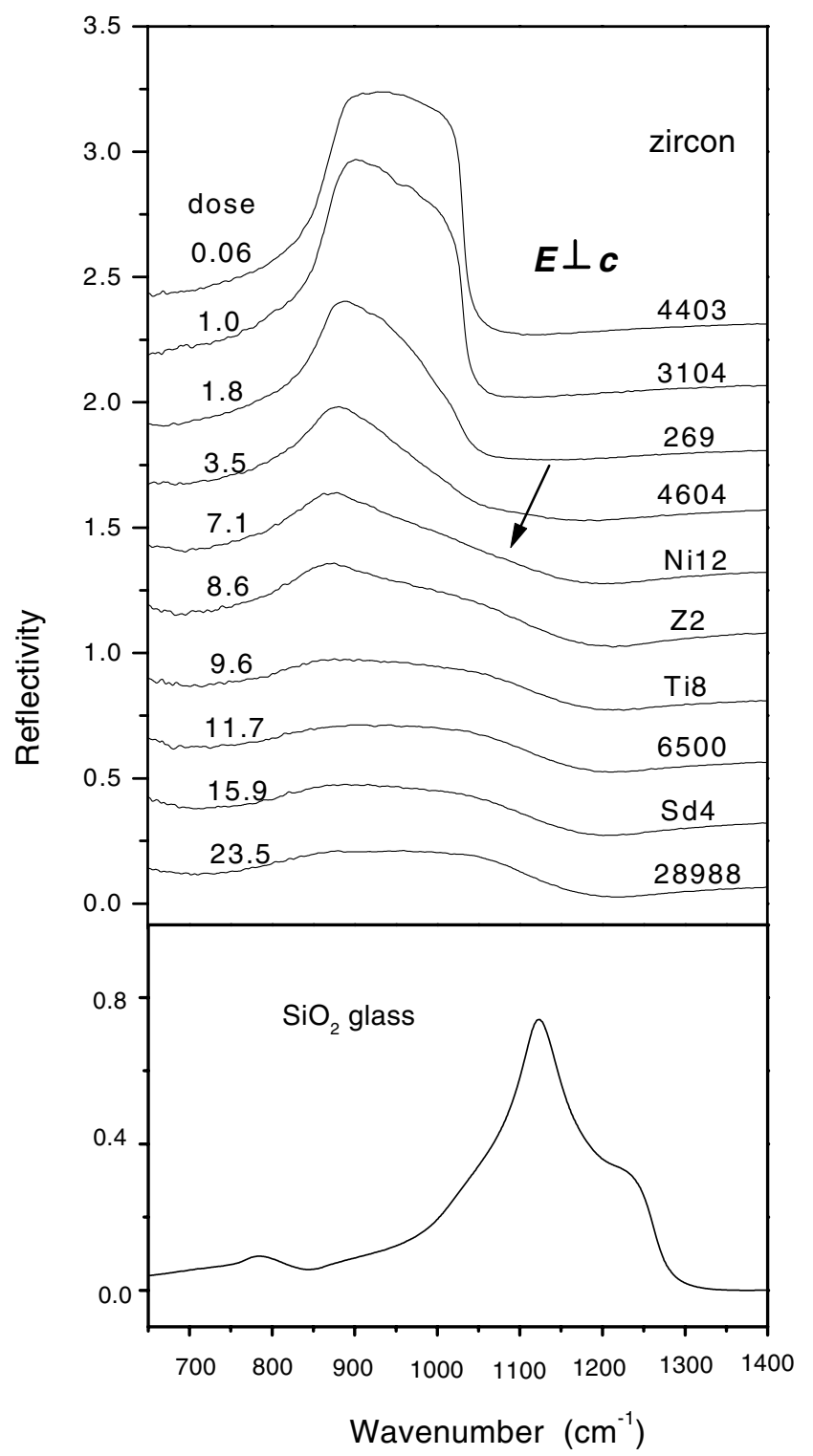

Figure 2. The effects of radiation damage on reflectivity $(\boldsymbol{E} \perp \boldsymbol{c})$ of zircon between 650 and $1400 \mathrm{~cm}^{-1}$. Spectra from samples $6500, \mathrm{Sd} 4$ and 28988 are from unorientated crystals (see text for details). Dosage is in units of $10^{18} \alpha$-events $\mathrm{g}^{-1}$. The spectrum of $\mathrm{SiO}_{2}$ glass is unpolarized. $\mathrm{SiO}_{2}$ glass shows very different spectral features from the rests in this range with characteristic $\mathrm{Si}-\mathrm{O}$ stretching vibrations.

Although the change of reflectivity with temperature is somewhat gradual, the reflectivity shows a relatively stronger increase between $1000 \mathrm{~K}$ and $1700 \mathrm{~K}$. The sample annealed at $1500 \mathrm{~K}$, $1600 \mathrm{~K}$ and $1700 \mathrm{~K}$ shows weak reflectivity maxima centred near $1020 \mathrm{~cm}^{-1}$ and $1150 \mathrm{~cm}^{-1}$ that are not consistent with crystalline $\mathrm{ZrSiO}_{4}$ (figure 4(a)). The anisotropy of sample $\mathrm{Z1}$ is restored during annealing, as evidenced by the recovery of orientational dependence of IR spectra along with the original crystallographic orientations. 


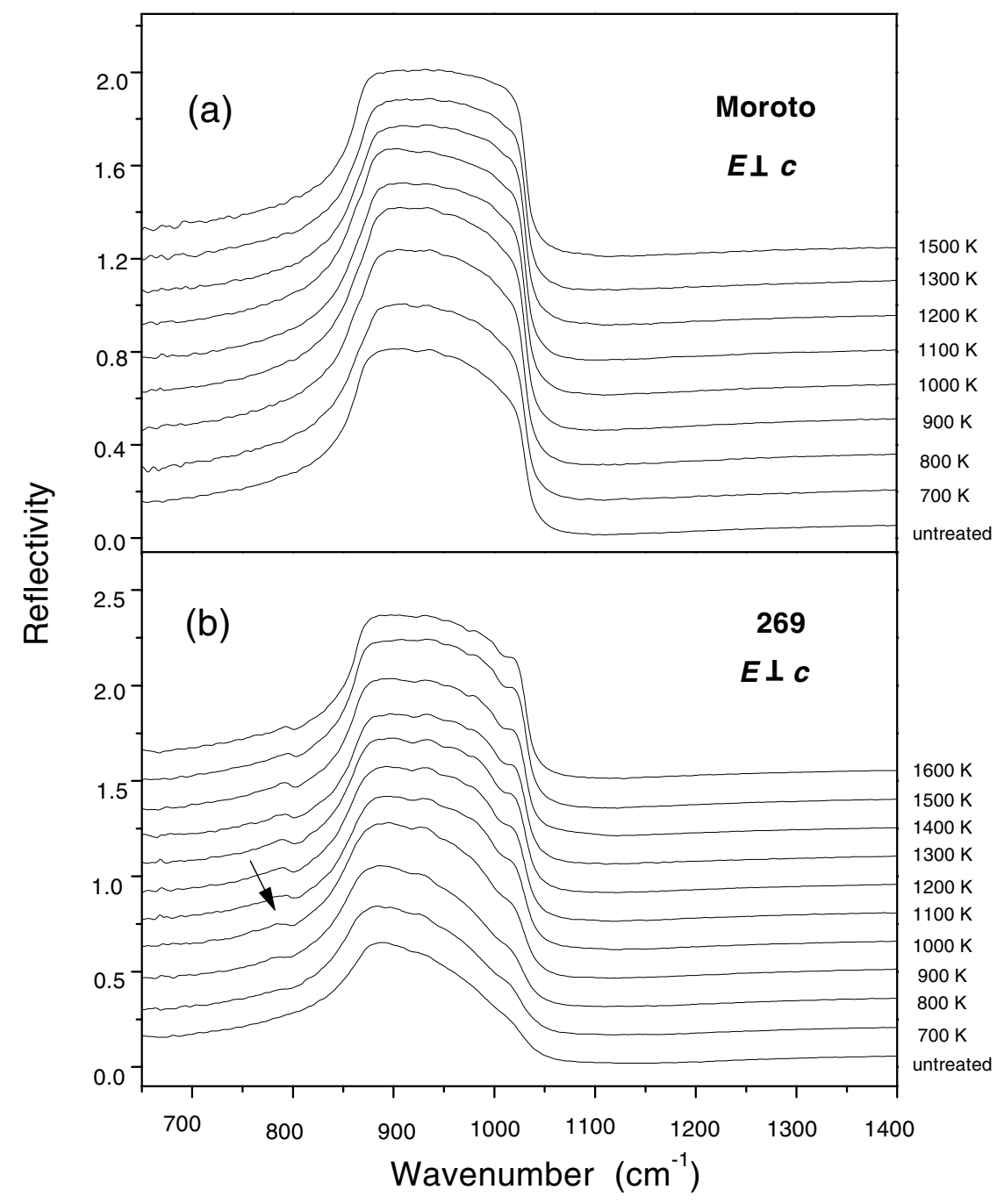

Figure 3. Annealing effects on polarized infrared spectra $(\boldsymbol{E} \perp \boldsymbol{c})$ between 650 and $1400 \mathrm{~cm}^{-1}$ : well crystallized sample Moroto (a), and weakly damaged sample 269 (b).

An extra peak located near $790 \mathrm{~cm}^{-1}$ was observed in moderately damaged zircon (samples 269 and Z1) between $800 \mathrm{~K}$ and $900 \mathrm{~K}$ (as indicated by arrows in figure 3(b) and 4(a)). A similar peak was reported in samples annealed at $1023 \mathrm{~K}$ [5]. This peak appears as a weak but detectable peak in the spectrum of Z1 and a resolved reflection maximum in sample 269 (figure 3(b) and 4(a)). For sample Z1 this additional signal almost disappears in the spectra above $1400 \mathrm{~K}$ (figure 4(a)) while it remains in sample 269 annealed at $1600 \mathrm{~K}$ (figure 3(b)). The absence of extra strong signals between 1000 and $1200 \mathrm{~cm}^{-1}$ in these annealed samples (figure 3(b)) suggests that this peak is not due to silica.

Unpolarized IR spectra were recorded for annealed Sd $4\left(\right.$ dose $=15.9 \times 10^{18} \alpha$-events $\left.\mathrm{g}^{-1}\right)$ because it was impossible to orient it crystallographically (see the experimental section). This highly damaged sample showed a very different recrystallization path from samples 269 and Z1 (with intermediate degrees of damage) (figure 5). No significant spectral variations were 


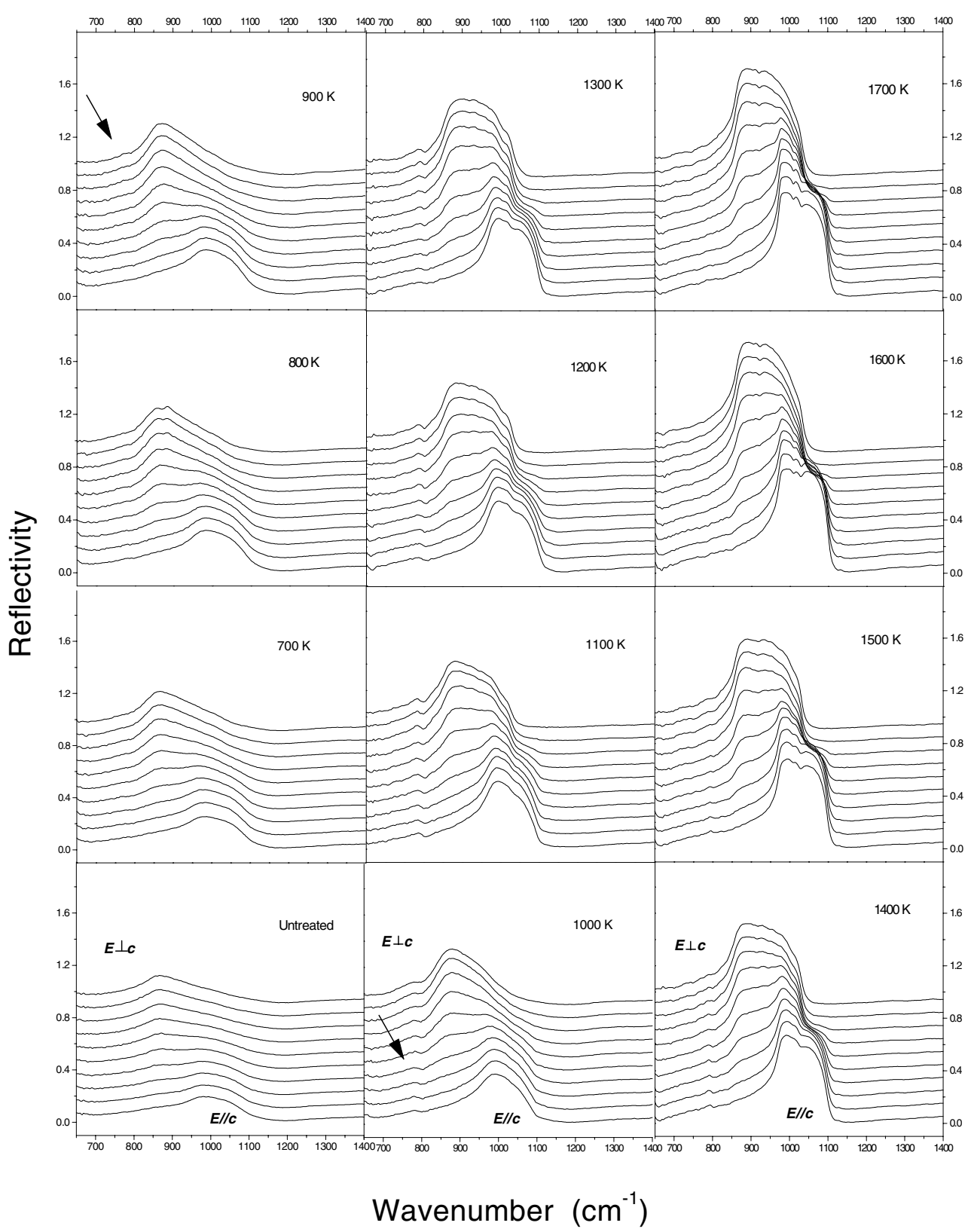

(a)

Figure 4. (a) Orientational dependence of polarized IR spectra of heavily damaged sample Z1 annealed between $292 \mathrm{~K}$ and $1700 \mathrm{~K}$. The interval of the angle between the $\boldsymbol{c}$ axis and $\boldsymbol{E}$ is $10^{\circ}$. (b) Temperature evolution of reflectivity at $990 \mathrm{~cm}^{-1}(\boldsymbol{E} \| \boldsymbol{c})$ and $890 \mathrm{~cm}^{-1}(\boldsymbol{E} \perp \boldsymbol{c})$.

seen at temperatures below $1000 \mathrm{~K}$. The spectrum at $1000 \mathrm{~K}$ shows a weak spectral maximum near 875 and $1060 \mathrm{~cm}^{-1}$. Annealing at $1100 \mathrm{~K}$ results in further increase of these two bands (figure 5). Additional reflection peaks between 1050 and $1250 \mathrm{~cm}^{-1}$ appear clearly in the spectrum at $1200 \mathrm{~K}$, and this is an indication of decomposition of $\mathrm{ZrSiO}_{4}$ into $\mathrm{SiO}_{2}$ and $\mathrm{ZrO}_{2}$. Major recrystallization of $\mathrm{ZrSiO}_{4}$ occurs between $1400 \mathrm{~K}$ and $1500 \mathrm{~K}$, as indicated by an 


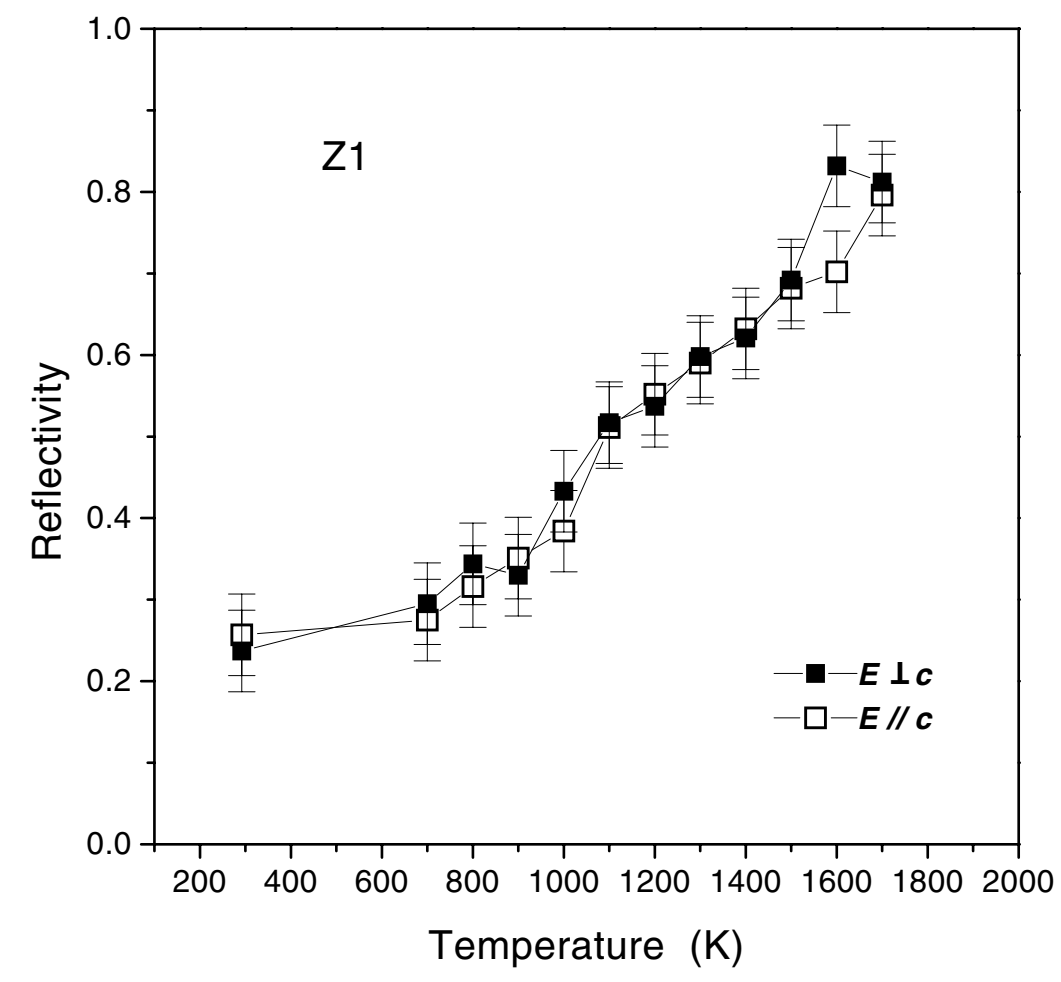

(b)

Figure 4. (Continued)

increase in reflectivity at $900 \mathrm{~cm}^{-1}$ (figure 5). Our results agree well with a recent Raman investigation of annealing $\alpha$-decay damage in zircon [6] that revealed similar decomposition and recrystallization processes. The unpolarized reflection spectra of Sd4 between 1600 and $1800 \mathrm{~K}$, in fact, look more like those spectra of crystalline samples with $\boldsymbol{E} \perp \boldsymbol{c}$ shown in figure 1. In the case of an unpolarized incident radiation this spectral feature can only be obtained when the sample is like a 'single crystal' and its $c$ axis is approximately parallel to the incident beam. This implies that the sample is somewhat anisotropic instead of polycrystalline because a polycrystalline sample is believed to give a spectrum mainly composed by spectra with $\boldsymbol{E} \| \boldsymbol{c}$ and $\boldsymbol{E} \perp \boldsymbol{c}$. X-ray measurement of the sample crystal annealed at $1800 \mathrm{~K}$ showed, consistent with the IR data, diffraction spots rather than powder rings suggesting that it is not a polycrystal, but a crystal containing mainly a number of big 'domains' or sub-crystals with closely aligned crystallographic orientations.

\section{Discussion}

Our experimental results show that oriental dependence of IR spectra persists even in samples with dose as high as $9.6 \times 10^{18} \alpha$-events $\mathrm{g}^{-1}$. No sample was found to be fully amorphous. This observation is in agreement with that of a recent single crystal x-ray study [9] which shows that Bragg peaks could be still detected in heavily damaged zircons. The recovery of anisotropy in highly damaged samples further proves that a number of crystalline domains must still exist in highly damaged samples. 


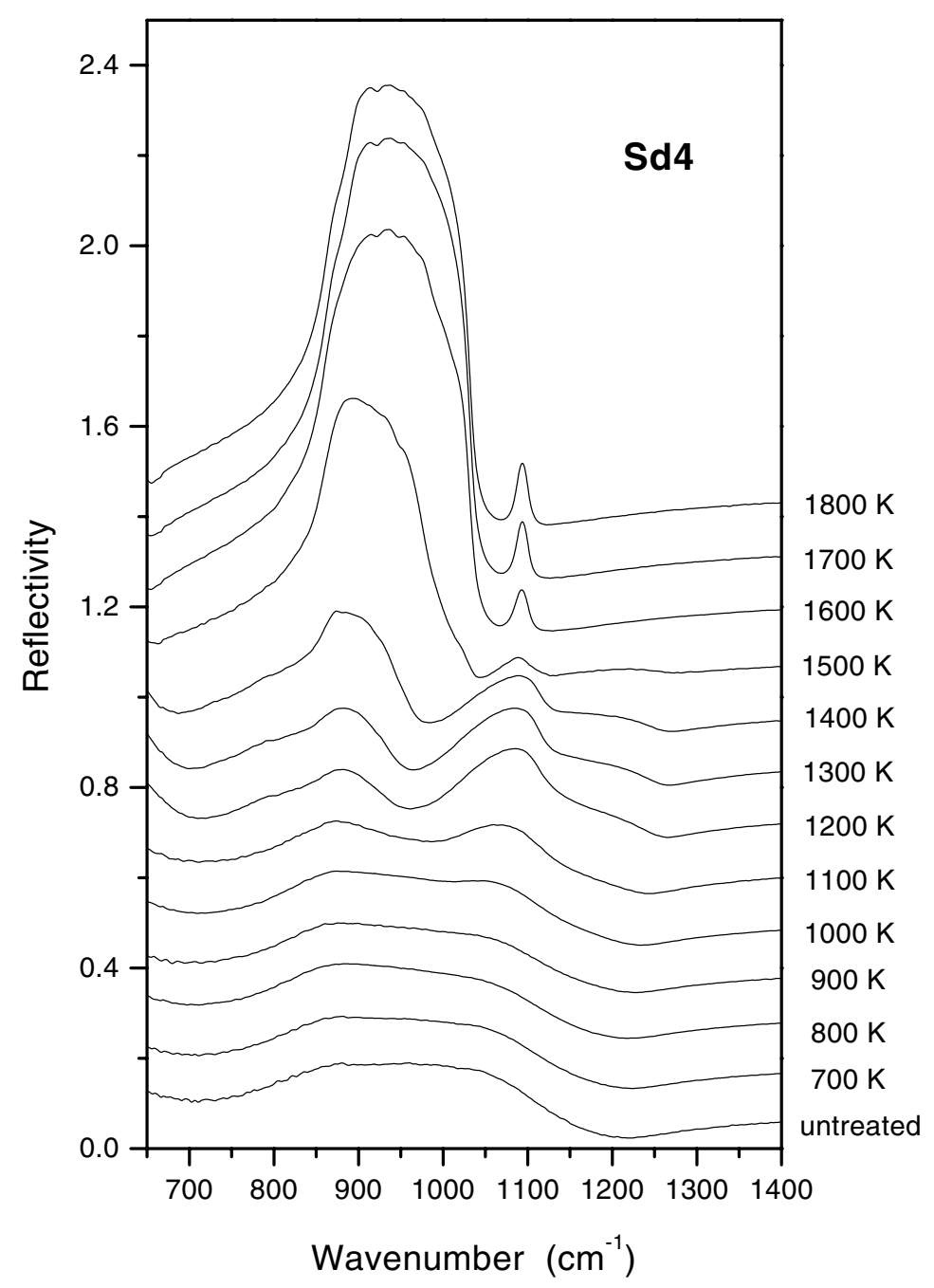

Figure 5. Unpolarized IR spectra of Sd4 $\left(15.9 \times 10^{18} \alpha\right.$-events $\left.\mathrm{g}^{-1}\right)$ between $292 \mathrm{~K}$ and $1800 \mathrm{~K}$. All the spectra are from the same crystal plate. The development of signal near $1095 \mathrm{~cm}^{-1}$ starting between $1000 \mathrm{~K}$ and $1100 \mathrm{~K}$ indicates the occurrence of $\mathrm{SiO}_{2}$ accompanied with unavoidable $\mathrm{ZrO}_{2}$ phase. With the appearance of $\mathrm{SiO}_{2}$ a spectral local reflectivity minimum occurs near $1260 \mathrm{~cm}^{-1}$ between $1200 \mathrm{~K}$ and $1500 \mathrm{~K}$ in contrast to a local minimum near $1200 \mathrm{~cm}^{-1}$ in the untreated sample. The appearance of a broad peak near $870 \mathrm{~cm}^{-1}$ near $1100 \mathrm{~K}$ indicates the presence of crystalline $\mathrm{ZrSiO}_{4}$.

Metamicitization causes extra signals between 1050 and $1150 \mathrm{~cm}^{-1}$ that we consider to be associated with the amorphized phase. These signals are detected at a radiation dose as low as about $3.5 \times 10^{18} \alpha$-events $\mathrm{g}^{-1}$ (powder absorption measurements show they appear at even lower doses). They gradually increase in intensity with further damage. The development of these extra signals implies a variation of local configuration of $\mathrm{SiO}_{4}$ tetrahedra or even new $\mathrm{SiO}_{4}$ linkage which accounts for the ${ }^{29} \mathrm{Si}$ NMR observation that metamictization in zircon caused a increase in chemical shift from $-81.6 \mathrm{ppm}$ (sample Moroto) to $-90 \mathrm{ppm}$ (a sample with estimated dose of $1-2 \times 10^{18} \alpha$-events $\mathrm{g}^{-1}$ ) [14]. 
The IR results confirm the recent Raman observations of Zhang et al [6], i.e. (1) the main crystal growth takes place near $1000 \mathrm{~K}$ in weakly and moderately damaged samples while it appears between 1400 and $1500 \mathrm{~K}$ in highly damaged samples; (2) additional vibrational bands appear near $800 \mathrm{~K}$. The recovery of anisotropy along original crystallographic orientations in damaged samples indicates that epitaxial growth plays a dominated role in the recrystallization process. The growth can be understood as the remaining crystalline domains of $\mathrm{ZrSiO}_{4}$ serving as seeds and their growth at high temperatures results in the recovery of original crystallographic orientations. These results agree well with recent results from polarized absorption IR spectroscopy of radiation-damaged titanite $[15,16]$. In these two investigations, these authors observed, through studying $\mathrm{OH}$ species, that thermal annealing leads to a recovery of original anisotropy in a damaged titanite crystal. A recovery of anisotropy was also reported in TEM studies $[17,18]$. Our observations imply that the damaged crystalline domains in metamict zircon remain approximately aligned along the original crystallographic orientations.

We shall now focus on the possible nature of the extra signal peaked near $790 \mathrm{~cm}^{-1}$ that appears in samples annealed at high temperatures. This peak is characterized by its relatively sharp (compared with $\mathrm{SiO}_{2}$ glass as shown in figure 2) and seemingly isotropic spectral features. As it does not appear in crystalline zircon (e.g. Moroto) and highly damaged sample Sd4 between $800 \mathrm{~K}$ and $900 \mathrm{~K}$, this signal is probably associated with radiation damage in samples with intermediate degrees of damage. Our data are consistent with the observations of Vance [5] who reported a similar observation: heating a moderately damaged Ceylon zircon samples of initial density ranging from 4.14 to $4.66 \mathrm{~g} \mathrm{~cm}^{-3}$ caused an absorption band near $800 \mathrm{~cm}^{-1}$, but this band was absent from more crystallized samples (density $=4.7 \mathrm{~g} \mathrm{~cm}^{-3}$ ). This peak also appeared in IR spectra of moderately damaged samples in other IR studies $[7,19]$ although its presence did not seem to have attracted much attention. Recently powder absorption spectra of a large number of zircon samples with moderate degrees of damage from various localities have been measured in Cambridge and these damaged samples all show a weak peak near $790 \mathrm{~cm}^{-1}$. According to theoretical and experimental work [13], $\mathrm{ZrSiO}_{4}$ structure does not have an IR band near $790 \mathrm{~cm}^{-1}$. The presence of this well defined IR band raises an important question of why moderately damaged zircon samples show such an additional IR band. In order to understand its physical nature and its possible roles in the damage process, one might need to answer why it is sharp and isotropic, and why upon heating it shows an increase in its intensity at temperatures as low as $800 \mathrm{~K}$ (compared with the epitaxial growth of $\mathrm{ZrSiO}_{4}$ near $1050 \mathrm{~K}$ and the decomposition of metamict $\mathrm{ZrSiO}_{4}$ into $\mathrm{SiO}_{2}$ and tetragonal $\mathrm{ZrO}_{2}$ between 1100 and $1200 \mathrm{~K}$ ). It is unknown whether this IR peak is associated with the peak splitting observed in x-ray diffraction [2] because the origin of the splitting is still unclear. Based on experimental data currently available, we consider this peak has the same physical origin as the additional Raman bands observed at high temperatures [6] because they appear in the same temperature range. The IR band and the additional Raman bands could indicate an unknown intermediate phase (of small volume proportion) or the structural distortions near the boundaries between the amorphized and crystalline regions. Further work is needed to test the two currently available hypotheses for their origin.

\section{Conclusion}

This polarized reflection IR spectroscopic study shows that $\alpha$-decay damage in zircon results in a gradual decrease in reflectivity and a loss of anisotropy of IR spectra. A gradual development of Si-O stretching signals between 1050 and $1150 \mathrm{~cm}^{-1}$ has been observed with increasing dose. This is considered as an indication of the formation of the amorphized phase. Annealing of damaged zircon at high temperatures leads to the recovery of anisotropy suggesting an 
epitaxial growth of $\mathrm{ZrSiO}_{4}$ along the original crystallographic orientations. The initial degree of damage in the sample may affect the recrystallization path. In weakly and moderately damaged zircon the major recrystallization takes place near $1000 \mathrm{~K}$. However, highly damaged zircon tends to decompose into $\mathrm{SiO}_{2}$ and $\mathrm{ZrO}_{2}$ near $1100 \mathrm{~K}$ and the growth of $\mathrm{ZrSiO}_{4}$ from the binary oxides occurs between 1400 and $1500 \mathrm{~K}$. These results are consistent with recent Raman observations. An additional IR signal peaked near $790 \mathrm{~cm}^{-1}$ was detected in moderately damaged samples annealed at temperatures higher than $800 \mathrm{~K}$. The appearance of this IR peak and previously reported Raman bands could suggest an unknown intermediate phase or structural distortions near the boundaries between the crystalline and amorphized regions.

\section{Acknowledgments}

The authors are indebted to the Natural History Museum, London, UK; the Sedgwick Museum of University of Cambridge, UK and the Mineralogisches Museum of Universität Hamburg, Germany for providing the samples used in this study. Financial support from EU Network on Mineral Transformations (contract number ERB-FMRX-CT97-0108) is gratefully acknowledged. RCE gratefully acknowledges support for Basic Energy Sciences/DOE (DEFG-02-97-ER45655).

\section{References}

[1] Weber W J, Ewing R C, Catlow C R A, delaRubia T D, Hobbs L W, Kinoshita C, Matzke H, Motta A T, Nastasi M, Salje E K H, Vance E R and Zinkle S J 1998 J. Mater. Res. 131434

[2] Holland H D and Gottfried D 1955 Acta Crystallogr. 8291

[3] Murakami T, Chakoumakos B C, Ewing R C, Lumpkin G R and Weber W J 1991 Am. Mineral. 761510

[4] Akhmanova M and Leonova L L 1961 Geochemistry 5416

[5] Vance E R 1975 Radiat. Eff. 241

[6] Zhang M, Salje E K H, Capitani G C, Leroux H, Clark A M, Schlüter J and Ewing R C 2000 J. Phys.: Condens. Matter 123131

[7] Woodhead J A, Rossman G R and Silver L T 1991 Am. Mineral. 7674

[8] Ellsworth S, Navrotsky A and Ewing R C 1994 Phys. Chem. Mineral. 21140

[9] Salje E K H, Chrosch J and Ewing R C 1999 Am. Mineral. 841107

[10] Ríos S and Salje E K H 1999 J. Phys.: Condens. Matter 118947

[11] Zhang M, Salje E K H, Farna I, Graem-Barber A, Danial P, Ewing R C, Clark A M and Leroux H 2000 J. Phys.: Condens. Matter 121915

[12] Ríos S, Salje E K H, Zhang M and Ewing R C 2000 J. Phys.: Condens. Matter 122401

[13] Dawson P, Hargreave M M and Wilkinson G F 1971 J. Phys. C: Solid State Phys. 4240

[14] Farnan I 1999 Phase Transitions B 6947

[15] Zhang M, Salje E K H, Malcherek T, Bismayer U and Groat L A 2000 Can. Mineral. 38119

[16] Salje E K H, Zhang M and Groat L A 2000 Phase Transitions at press

[17] McLaren A C, Fitz J D and Williams I S 1994 Geochim. Cosmochim. Acta 58993

[18] Capitani G C, Leroux H, Doukhan J C, Ríos S, Zhang M and Salje E K H 2000 Phys. Chem. Mineral. at press

[19] Biagini R, Memmi I and Olmi F 1997 N. Jahrbuch Mineral. Monatshefte 257 